\title{
SENSITIVITY OF THE THICKNESS OF ARCTIC SEA ICE TO THE OPTICAL PROPERTIES OF CLOUDS
}

\author{
by \\ Judith A. Curry \\ (Earth System Science Center and the Department of Meteorology, The Pennsylvania State University,
} 503 Walker Building, University Park, PA 16802, U.S.A.)

and

Elizabeth E. Ebert

(Bureau of Meteorology Research Centre, GPO Box 1289K, Melbourne, Victoria 3001, Australia)

\section{ABSTRACT}

The sensitivity of Arctic sea-ice thickness to the optical properties of clouds is investigated. Pollution aerosol has the potential to modify cloud optical properties significantly, which in turn could perturb the radiation balance at the surface of the pack ice. A one-dimensional thermodynamic model of sea ice is employed in this study. Radiative fluxes are parameterized in terms of integrated liquid (ice) water path and the particle effective radius. Results from these calculations show that, for a constant liquid (ice) water path, increasing cloud droplet concentration and the associated reduction in drop size results in a significantly altered surface radiation balance, contributing to an increase in sea-ice thickness. Considerable sensitivity has also been shown of the surface radiation balance to the frequency of occurrence and optical depth of lower tropospheric ice crystals that are present during the cold part of the year.

\section{INTRODUCTION}

The increasing amount of air pollution transported from mid-latitudes to the Arctic has become an issue of significant concern (Stonehouse, 1986). Considerable attention has been given to the perturbation of the Arctic radiation budget associated with the aerosol. However, the dominant radiative perturbation associated with aerosol may not be due to its direct interaction with radiation, but rather indirectly due to its modification of cloud nucleation and therefore cloud optical properties. Increased cloud condensation nuclei $(\mathrm{CCN})$ may result in a larger number of small-sized droplets, increasing the cloud reflectivity (Twomey, 1977). Ice nucleation may also be affected by pollution aerosol.

Toward assessing the possible impact of pollution aerosol on the thickness of the Arctic pack ice, the surface radiative flux in a one-dimensional thermodynamic model of sea ice is perturbed to account for modifications to the cloud microphysical properties.

\section{PROPERTIES OF ARCTIC CLOUDS}

The annual cycle of mean monthly fractional cloud cover in the central Arctic shows a summertime maximum as high as $90 \%$, with wintertime values slightly less than $50 \%$ (Huschke, 1969). The variability of the total cloudcover amount is dominated by the variability of low-level clouds, with the frequency of occurrence and total cloud amount increasing to their maximum summertime values over a short transitional period during spring. Curry (1988) and Hoff and Leaitch (1589) have recently questioned
TABLE I. MICROPHYSICAL PROPERTIES OF SUMMERTIME ARCTIC CLOUDS

$\begin{array}{lccc}\text { Date Location } & \begin{array}{c}\text { Liquid water } \\ \text { concentration }\end{array} & \begin{array}{c}\text { Droplet } \\ \text { density }\end{array} & \begin{array}{c}\text { Average drop } \\ \text { diameter }\end{array} \\ & \mathrm{g} \mathrm{m}^{-3} & \mathrm{~cm}^{-3} & \mu \mathrm{m} \\ 1 \quad \text { Soviet Arctic } & 0.05-0.3 & - & 14-20 \\ { }^{2} 9 / 59 \text { Soviet Arctic } & 0.01-0.15 & 18-91 & 11 \\ { }^{3} 9 / 71 \text {, Barrow } & 0.1-0.2 & 90 & 13.5 \\ 4 / 72 & & & 100-500 \\ { }^{4} 6 / 80 \text { Beaufort Sea } & 0.2-0.3 & \\ \\ 1 \text { Dergach and others (1960) } \\ 2 \text { Koptev and Voskresenskii (1962) } \\ 3 \text { Jayaweera and Ohtake (1973) } \\ 4 \text { Curry (1986) }\end{array}$

wintertime low-level cloud statistics for the Arctic. Low-level ice crystal clouds, which are abundant during the cold half of the year, are not included in these statistics, due to difficulties in observing these ice crystals both from the surface and from satellite, and also due to ambiguities of cloud classification in the polar regions.

Microphysical properties

Cloud optical properties depend on the amount of condensed water, the size and shape of the cloud particles, and the phase of the particles (liquid or ice). A summary of the observed cloud microphysical properties for summertime Arctic stratus is given in Table $I$, showing a considerable range between the different studies. In particular, the recent measurements of Curry (1986) indicate larger droplet concentrations and smaller average droplet radii than earlier measurements. $\mathrm{CCN}$ in the Arctic are believed to consist predominantly of sulphate from both marine and pollution sources. Differences in the concentration and size distribution of sulphate aerosols as reflected in the different drop sizes and droplet concentrations may be associated with increasing anthropogenic pollution, although natural variations associated with regional differences and the seasonal phytoplankton productivity cycle may also be factors.

During the cold half of the year, when sunlight is largely absent, temperatures are sufficiently cold that any condensate is predominantly crystalline. The microphysical properties of these ice crystals has been reviewed by Curry and others (1990). Variations in the temperature and relative humidity at which ice crystals form, and also in ice crystal 
size and concentration, will depend to a substantial degree on aerosol concentration and composition. However, it has been shown generally, and in the Arctic specifically during springtime (Borys, 1983), that polluted air is typically deficient in ice-forming nuclei (IFN). This is believed to be associated with an increased amount of sulphate particles in the polluted air which coagulate with the ice-forming nuclei and effectively deactivate them, since sulphate particles act as poor IFN. It is hypothesized here that ice nucleation may be relatively enhanced during winter, due to a decrease in the oxidation of $\mathrm{SO}_{2}^{=}$in the relative absence of sunlight and liquid water.

\section{Radiative properties}

The most extensive investigation to date of the radiative properties of the summertime Arctic stratus was made during the Arctic Stratus Experiment, which was conducted during July 1980 over the Beaufort Sea (Herman and Curry, 1984; Curry and Herman, 1985). The singlescattering properties of the cloud drops (e.g. volume extinction coefficient and single-scatter albedo) as well as the cloud bulk radiative properties (i.e. reflectance, transmittance, absorbancy, and emittance) were all found to show significant dependence upon the drop-size distribution. Larger droplet concentrations and smaller drop sizes result in increased shortwave reflectance and longwave emittance, with decreases in shortwave transmittance. Although the dependence of longwave emissivity on drop-size distribution is typically ignored due to the infrared opacity of most clouds, Curry and Herman (1985) found that the liquid water path in Arctic stratus was frequently less than $20 \mathrm{~g} \mathrm{~m}^{-2}$ even during summer, in the range where emissivity is sensitive to drop-size distribution.

Observations of radiative properties of Arctic clouds during seasons other than summer are sparse, particularly for the wintertime situation with low-level crystalline clouds. Because of the virtual absence of sunlight, the dominant radiative effect in wintertime due to clouds is in the longwave radiative fluxes. The only in situ observations of radiative fluxes in wintertime Arctic clouds that we are aware of are those reported by Witte (1968) for the $8-14 \mu \mathrm{m}$ spectral region. Calculations using the ice crystal concentrations and size spectra observed by Witte (1968) were recently made by Curry and others (1990), showing an increase in the surface longwave flux of almost $80 \mathrm{~W} \mathrm{~m}^{-2}$ over the clear sky case.

\section{THE MODEL}

It was shown by Herman and Curry (1984) and Curry and Herman (1985) that the longwave and shortwave properties of liquid water clouds depend primarily on the vertically integrated amount of liquid water (liquid water path, $L W P$ ) and the equivalent radius, $r_{\mathrm{e}}$, of the drop-size distribution. The equivalent radius is the ratio of the 3 rd to the 2 nd moment of the drop-size distribution, yielding an effective mean droplet radius weighted by the cross-sectional area of the drops.

The shortwave cloud extinction optical depth, ${ }^{\tau}$ ext, for liquid water clouds can be determined from $\tau_{\text {ext }}=1.5 L W P / r_{\mathrm{e}}$. For ice clouds a similar expression is employed, $\tau_{\text {ext }}=1.5 I W P / r_{\mathrm{e}}$, where $I W P$ is the vertically integrated ice water path and $r_{\mathrm{e}}$ is the volume equivalent radius of the ice crystals. The multiple-scattering approximations employed to determine the shortwave reflectance and transmittance were chosen by considering the comparisons made by King and Harshvardhan (1986). The broadband shortwave reflectance and transmittance for optically thick water clouds are determined here from asymptotic theory, using values of the single-scattering albedo equal to 0.995 and the asymmetry factor equal to 0.85 . For optically thin water clouds and ice clouds that occur during winter, the delta-Eddington approximation for the cloud reflectance and transmittance is used. A single-scattering albedo of 0.984 and asymmetry factor of 0.794 are used for the ice crystals. Effects of multiple reflections between the cloud and snow/ice surface are accounted for.

Broad-band infrared emittance, $\varepsilon$, is parameterized for liquid water clouds after Curry and Herman (1985) to be $\varepsilon=1-\exp \left[-0.363 \exp \left(-0.234 r_{\mathrm{e}}\right) L W P\right]$, where the units of $r_{\mathrm{e}}$ and $L W P$ are $\mu \mathrm{m}$ and $\mathrm{g} \mathrm{m}^{-2}$, respectively. For ice clouds, the absorption coefficient of $0.06 \mathrm{~m}^{2} \mathrm{~g}^{-1}$ based on the values used by Starr and Cox (1985) for cirrus clouds is employed, to yield the infrared ice cloud emittance:

$$
\varepsilon=1-\exp [-0.06 I W P]
$$

The sea-ice model employed here is based on the Maykut and Untersteiner (1971) one-dimensional thermodynamic model of sea ice, and includes a lead parameterization. Details of the model solution are described by Ebert and others (in preparation). A variety of sea-ice model parameters have been employed by different investigators. The largest uncertainties seem to be associated with the albedo of bare melting ice, the oceanic heat flux, the fraction of the net absorbed solar radiation penetrating into the ice interior, and the minimum lead fraction. The model parameters that we have chosen for the present calculations are as follows: a fraction of the absorbed shortwave radiation penetrating the ice equal to 0.32 ; oceanic heat flux equal to zero; and a minimum lead fraction of 0.005 . The surface albedo parameterization follows that proposed by Shine and Henderson-Sellers (1984), with the exception of the summertime ice albedo. The summertime melting ice albedo, $\alpha_{\mathrm{m}}$, is determined from $\alpha_{m}=0.56(1-p)+0.29 p$, where $p$, the melt-pond fraction, has a maximum value of 0.35 that occurs $30 \mathrm{~d}$ after the snow has melted. Snowfall and surface sensible and latent heat fluxes are based on the values provided by Fletcher (1965), with the cloud fraction taken after Huschke (1969). Clear-sky surface radiative fluxes are parameterized from off-line model calculations, with the cloud radiative forcing calculated explicitly in the model. Cloud temperatures are determined using values interpolated from Oort (1983).

\section{EXPERIMENTS AND RESULTS}

Starting from the 1 January initial sea-ice thickness and a temperature profile corresponding to Maykut and Untersteiner's equilibrium sea-ice conditions, the model is integrated until the annually-averaged sea-ice thickness changes by less than $1 \mathrm{~mm}$ from year to year to determine the equilibrium annually-averaged sea-ice thickness.

\section{Baseline case}

A base-line case is defined to parallel present-day conditions closely, using observed cloud optical properties. The cloud geometrical depth is set to $300 \mathrm{~m}$ and the droplet equivalent radius, $r_{\mathrm{e}}$, is specified to be $7.5 \mu \mathrm{m}$. Cloud liquid water content is specified to be a fraction 0.57 of the adiabatic liquid water content. The parameterized liquid water path of the low-level clouds thus ranges from a low value of $6 \mathrm{~g} \mathrm{~m}^{-2}$ during February to a high value of $27 \mathrm{~g} \mathrm{~m}^{-2}$ toward the end of June. A value of $16 \mathrm{~g} \mathrm{~m}^{-2}$ for $I W P$ is used for the ice crystals, which are prescribed to occur during the period when the air temperature is less than $258 \mathrm{~K}$ (October through April). The fractional occurrence of the ice crystals is taken to be 0.7 when air temperature is less than $250 \mathrm{~K}$ (mid-December through midMarch), decreasing linearly to zero when air temperature exceeds $258 \mathrm{~K}$. Although there is considerable uncertainty associated with the frequency of occurrence of the wintertime ice crystals and their microphysical properties, the above specification represents the best estimate that we are able to make at present.

For the base-line case, the annually-averaged equilibrium thickness of the sea ice is $2.95 \mathrm{~m}$, with a late winter maximum of $3.30 \mathrm{~m}$ and a late summer minimum of $2.43 \mathrm{~m}$. We attribute the increased annual amplitude when compared with the Maykut and Untersteiner results primarily to: inclusion of the lead parameterization which has a strong impact on bottom accretion; a lower value of bare melting ice albedo which impacts surface ablation; and the use of slightly different radiative forcing. The relatively simple cloud model used here results in some differences in the net surface radiation when compared with the values given by Fletcher (1965) that were used by Maykut and Untersteiner. In particular, the values of wintertime longwave flux are larger than those cited by Fletcher; 


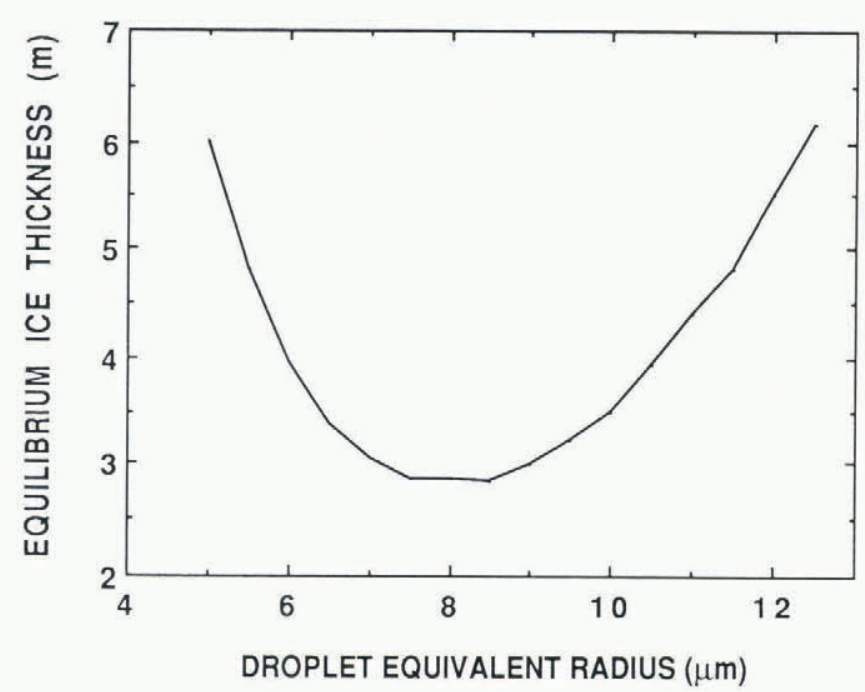

Fig. 1. Sensitivity of the annually-averaged equilibrium sea-ice thickness to droplet equivalent radius.

Fletcher's values were calculated rather than measured, and did not include the effects of ice crystals.

\section{Sensitivity to drop-size distribution}

To test the sensitivity of sea-ice thickness to changes in drop-size distribution that might possibly arise from increased pollution, the value of $r_{\mathrm{e}}$ is varied, keeping cloud depth, temperature, and liquid water content the same as for the base-line case. The values of $r_{\mathrm{e}}$ are varied from $13 \mu \mathrm{m}$, reflecting that which might be representative for a stratiform cloud in a remote maritime region, to $5 \mu \mathrm{m}$, representative of highly polluted air.

Figure 1 shows the variation of the annually-averaged equilibrium thickness of sea ice with droplet-equivalent radius. The minimum sea-ice thickness is seen to occur for $r_{\mathrm{e}}=8.5 \mu \mathrm{m}$, with the modeled sea-ice thickness increasing for values of $r_{\mathrm{e}}$ both greater than and less than $8.5 \mu \mathrm{m}$. This somewhat surprising result is explained by considering the combined effects on the shortwave and longwave fluxes of changing $r_{\mathrm{e}}$. Increasing cloud optical thickness (associated with a decrease in $r_{\mathrm{e}}$ ) will result in a decrease in cloud shortwave transmissivity (decreasing the shortwave flux at the surface) and an increase in cloud longwave emissivity (increasing the longwave flux at the surface). Examination of the annual cycle of the radiative fluxes shows that the dominant radiative perturbation associated with decreasing $r_{\mathrm{e}}$ occurs during the summer. The shortwave perturbation is dominant at small values of $r_{\mathrm{e}}$, since the summertime clouds have a longwave emissivity of nearly unity at the smaller values of $r_{\mathrm{e}}$. This longwave emissivity varies negligibly as $r_{\mathrm{e}}$ is decreased. As $r_{\mathrm{e}}$ increases, however, the longwave perturbation becomes increasingly important since the clouds become less opaque, affecting a larger part of the annual cycle than does the shortwave perturbation.

The case that is believed to correspond most closely to present-day conditions, $r_{\mathrm{e}}=7.5 \mu \mathrm{m}$, occurs near the minimum equilibrium ice thickness in Figure 1. Increasing the amounts of pollution aerosol is expected to reduce $r_{\mathrm{e}}$, resulting in a significantly altered surface radiation balance, contributing to increasing the thickness of sea ice. The sea ice appears to be less sensitive to increased values of $r_{\mathrm{e}}$.

\section{Sensitivity to occurrence of ice crystals}

Lower tropospheric ice crystals are not included in the cloud fraction values specified by Huschke (1969), which are used as forcing for this model. Nevertheless, surface radiative fluxes are believed to be substantially modified by these ice crystals during the cold half of the year. Figure 2 shows the sensitivity of sea-ice thickness to the frequency of occurrence of ice crystals and the ice water path during the cold half of the year. Although there is considerable uncertainty about the frequency of occurrence of ice crystals and their optical depth, these experiments indicate substantial sensitivity of sea-ice thickness to the ice crystal properties.

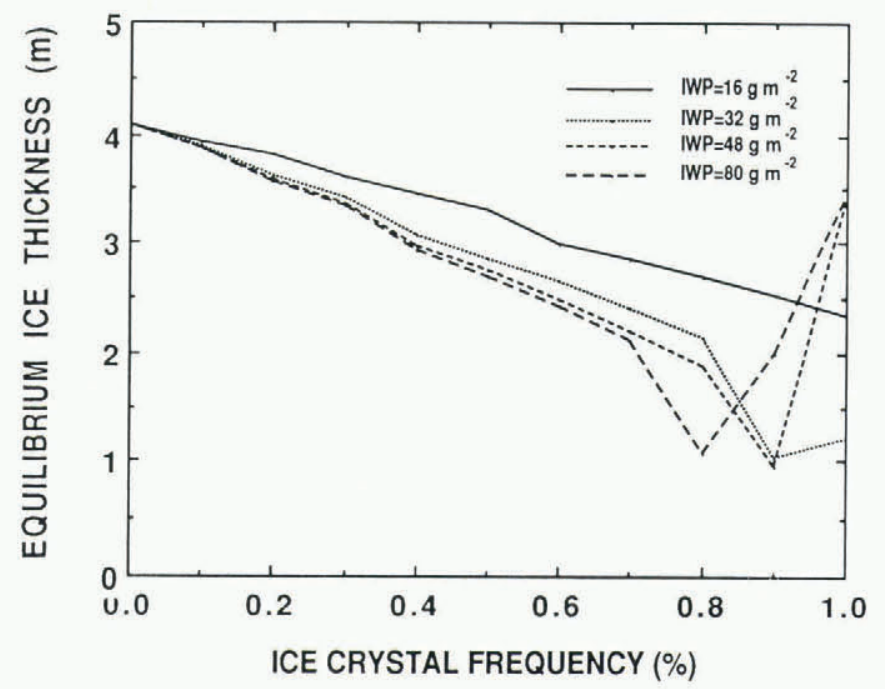

Fig. 2. Sensitivity of the annually-averaged equilibrium sea-ice thickness to the frequency of occurrence of lower tropospheric ice crystals during the cold part of the year, as a function of the ice-water path.

In the absence of ice crystals the equilibrium sea-ice thickness is $4.1 \mathrm{~m}$, compared to $2.95 \mathrm{~m}$ for the base-line case. Since the ice crystals are present only during the cold half of the year, infrared effects dominate, resulting in a general decrease in ice thickness with increasing amounts of ice crystals. For ice crystal frequencies approaching $80 \%$ for the higher values of $I W P$, the ice totally melts during the summer, with the annually-averaged sea-ice thickness near $1 \mathrm{~m}$. For these higher values of $I W P$, the sea-ice thickness increases again as the ice crystal frequency approaches $100 \%$. This increase is associated with the solar radiation effects that occur during early spring. At increased ice water paths and ice crystal frequency, layers of ice crystals during springtime become sufficiently thick to reduce the solar flux received at the surface significantly and thus delay the springtime warming.

\section{CONCLUSIONS}

This paper has addressed the possibility that increasing amounts of air pollution in the central Arctic may be modifying cloud nucleation, and potentially the thickness of the sea ice via perturbations to the surface radiative flux. In addition to pollution aerosol, aerosols from volcanic eruptions, dust storms, and other natural geophysical events also have the potential to modify cloud optical properties and thus sea-ice thickness.

Using a simple one-dimensional thermodynamic model of sea ice, it has been shown that sea-ice thickness will increase as a result of decreasing the droplet-equivalent radius from its currently observed value of $7.5 \mu \mathrm{m}$. Considerable sensitivity has been shown of the ice thickness to the frequency of occurrence and optical depth of lower tropospheric ice crystals that are present during the cold part of the year. In the interpretation of these results, the oversimplifications involved in the model calculations and the large uncertainties associated with many aspects of the characteristics of sea ice and the Arctic clouds should be kept in mind. In particular, no feedbacks between the sea ice and clouds have been included. The results of these experiments are therefore more accurately interpreted as first order sensitivity tests, rather than as true representations of the actual sea-ice system.

These experiments address only one aspect of the possible perturbation to sea-ice thickness associated with increasing pollution aerosol in the Arctic, namely the effect of modifying cloud optical proprerties. Additional aspects include modifications to the amount of snowfall, snow surface albedo, and boundary layer stability. To assess the full impact of pollution aerosol, a coupled sea-ice atmosphere model must be developed that can simultaneously address all of these processes including the feedback mechanisms. Work towards this end is currently under way. 


\section{ACKNOWLEDGEMENTS}

Comments from T. Ackerman, E. Andreas, and the anonymous reviewers helped improve the clarity of this manuscript. Technical assistance from E. Horvath and C. Ardeel is appreciated. This research has been supported by U.S. National Science Foundation grant DPP-8858830.

\section{REFERENCES}

Borys, R.D. Unpublished. The effects of long-range transport of air pollutants on Arctic cloud-active aerosol. (Ph.D. thesis, Colorado State University, 1983.)

Curry, J.A. 1986. Interactions among turbulence, radiation and microphysics in Arctic stratus clouds. J. Atmos. Sci., 43(1), 90-106.

Curry, J.A. 1988. Arctic cloudiness in spring from satellite imagery: some comments. J. Climatol., 8(5), 533-538.

Curry, J.A. and G.F. Herman. 1985. Infrared radiative properties of summertime Arctic stratus clouds. J. Climate Appl. Meteorol., 24, 525-538.

Curry, J.A., F.G. Meyer, L.F. Radke, C.A. Brock, and E.E. Ebert. 1990. Occurrence and characteristics of lower tropospheric ice crystals in the Arctic. Int. J. Clim.

Dergach, A.L., G.M. Zabrodskiy, and V.G. Morachevskiy. 1960. The results of a complex investigation of the type st-sc clouds and fogs in the Arctic. Akad. Nauk SSSR Byull. Geofizicheskaya, Ser. 1, 66-80.

Ebert, E.E., J.A. Curry, and G.F. Herman. In preparation. Feedback mechanisms in a one-dimensional coupled model of sea ice and the atmospheric boundary layer.

Fletcher, J.O. 1965. The heat budget of the Arctic basin and its relation to climate. Santa Monica, CA, The Rand Corporation. (R-444-PR.)

Herman, G.F. and J.A. Curry. 1984. Observational and theoretical studies of solar radiation in Arctic stratus clouds. J. Climate Appl. Meteorol., 23, 5-24.

Hoff, R.M. and W.R. Leaitch. 1989. Ground-based cirrus clouds in the Arctic. In AMS Symposium on the Role of Clouds in Atmospheric Chemistry and Global Climate. Preprint volume, 324-327.

Huschke, R.E. 1969. Arctic cloud statistics from "air-calibrated" surface weather observations. Santa Monica, CA, The Rand Corporation. (RM-6173-PR.)

Jayaweera, K.O.L.F. and T. Ohtake. 1973. Concentration of ice crystals in Arctic stratus clouds. J. Rech. Atmos., 7, 199-207.

King, M.D. and Harshvardhan. 1986. Comparative accuracy of selected multiple scattering approximations. J. Atmos. Sci., 43, 784-801.

Koptev, A.P. and A.I. Voskresenskiy. 1966. On the radiation properties of clouds. Santa Monica, CA, The Rand Corporation. (Memo RM-5003.) [Translation from original Russian.]

Maykut, G.A. and N. Untersteiner. 1971. Some results from a time-dependent thermodynamic model of sea ice. $J$. Geophys. Res., 76(6), 1550-1575.

Oort, A.H. 1983. Global atmospheric circulation statistics 1958-1973. NOAA Prof. Pap. 14.

Shine, K.P. and A. Henderson-Sellers. 1984. The sensitivity of a thermodynamic sea ice model to changes in surface albedo parameterization. J. Geophys. Res., 90, 22432250 .

Starr, D.O. and L.D. Cox. 1985. Cirrus clouds. Part I. A cirrus cloud model. J. Atmos. Sci., 42, 2663-2681.

Stonehouse, B., ed. 1986. Arctic air pollution. Cambridge, Cambridge University Press.

Twomey, S. 1977. Atmospheric aerosols. Amsterdam, Elsevier.

Witte, H.J. Unpublished. Airborne observations of cloud particles and infrared flux density in the Arctic. (M.S. thesis, University of Washington, 1968.) 